\title{
Research on multi-terminal traveling wave fault location method in complicated networks based on cloud computing platform
}

\author{
Feng Deng ${ }^{1 *}$, Xiangjun Zeng ${ }^{1}$ and Lanlan Pan ${ }^{2}$
}

\begin{abstract}
Cloud computing technology is used in traveling wave fault location, which establishes a new technology platform for multi-terminal traveling wave fault location in complicated power systems. In this paper, multi-terminal traveling wave fault location network is developed, and massive data storage, management, and algorithm realization are implemented in the cloud computing platform. Based on network topology structure, the section connecting points for any lines and corresponding detection placement in the loop are determined first. The loop is divided into different sections, in which the shortest transmission path for any of the fault points is directly and uniquely obtained. In order to minimize the number of traveling wave acquisition unit (TWU), multi-objective optimal configuration model for TWU is then set up based on network full observability. Finally, according to the TWU distribution, fault section can be located by using temporal correlation, and the final fault location point can be precisely calculated by fusing all the times recorded in TWU. PSCAD/EMTDC simulation results show that the proposed method can quickly, accurately, and reliably locate the fault point under limited TWU with optimal placement.
\end{abstract}

Keywords: Wide Area Network, Fault location, Traveling wave, Junction Point between Sections, Cloud computing platform

\section{Introduction}

With the development of smart grid, safe and reliable control and operation of the complicated grid have become more and more important. However, the existing fault location technology and massive data processing capacity cannot meet the demand of smart grid.

Traveling wave fault location has a fast response speed and is immune to distributed capacitance, system oscillation, and current transformer saturation, etc. Thus, compared to other kinds of fault location methods, it has obvious theoretical advantages. With the advancement of modern traveling wave theory and related technologies, traveling wave fault location has had significant development [1-5] and has a good prospect in practical applications.

\footnotetext{
* Correspondence: df_csust@126.com

'Changsha University of Science and Technology, Changsha, Hunan, China Full list of author information is available at the end of the article
}

Currently, traveling wave fault location method can be divided into two categories: local-based $[6,7]$ and network-based [8-14]. The local-based traveling wave fault location method is executed on a single line, which can be significantly affected by the operating status of the locating devices and interference signals. The method has high risk of miss-trip or mal-operation, and thus the reliability of fault location can't be guaranteed. Networkbased traveling wave fault location method collects large amount of data from TWU installed in all the substations, and fuses all the information to determine the exact fault position. This significantly improves the fault location reliability and guarantees high accuracy. Traveling wave fault location method based on the graph theory was presented in [8]. The complicated network can be simplified by using Floyd algorithm, and the initial traveling wave arrival times are uniquely matched with the transmission path. The exactly fault point is then calculated by information 
fusion technology. On this basis, the transmission path for the initial traveling wave is found by using adjacent point optimization algorithm in [9]. Based on the positive proportional relationship between transmission distance and transmission time, linear fitting is executed and the fault location is realized. However, all these methods need massive data pre-processing for each single fault, and loop simplification, data matching, and information fusion, which are complicated and unfeasible.

Based on the technical condition of smart grid and cloud computing, a multi-terminal traveling wave fault location algorithm for complicated networks is proposed based on cloud computing platform. According to the topology structure, the complicated loop can be divided into several sections, in which the shortest traveling wave transmission path is determined, and multi-objective optimal TWU configuration is realized based on network full observability. Because of the correlation of the initial traveling wave arrival times, fault section can then be defined. Finally, the exactly fault position is determined by converting all the recorded initial traveling wave arrival times and fusing converted ones. The proposed method determines the fault section and realizes optimal TWU configuration. It can directly obtain the shortest transmission path, which omits network simplification and the matching process for the shortest transmission path. The method guarantees accurate fault location and improves reliability, and only requires to install a portion of TWU in the complicated network.

\section{Methods}

\subsection{Multi-terminal traveling wave fault location network based on cloud computing platform}

Cloud computing [15-17] has the advantages of flexible service, resource pooling, service on demand, generalization access, which can satisfy the large-scale and parallel computation characteristics for power systems. It makes use of dispersive resources in different regions and unites the management by resources pooling. The way of management can also meet the uncertainty of computation. In the cloud computing platform, it allocates calculation resources base on the scale of the terminal load, thus avoiding the decrease of service quality. There is no need for precise understanding of the computing equipment, which significantly reduces operation complexity for users.

Figure 1 shows the multi-terminal traveling wave fault location network based on cloud computing platform. When a fault occurs, traveling wave-front is recorded in the substations which have TWU installed. Using the GPS/BEIDOU satellites timing system, highly accurate synchronous traveling wave arrival times are obtained. Through the wireless communication system, large quantities of data are transmitted into the cloud computing platform where current data resources and processor resources are integrated, and fault location is realized in "cloud" by scheduling algorithms.

Thus, traveling wave fault location platform based on cloud computing is developed, and the multi-terminal traveling wave fault location network is built in this paper, as shown in Fig. 2. When a fault occurs, the fault data, such as the initial traveling wave front arrival times synchronized by GPS/Beidou satellite, the magnitude and phase angle of the voltage and current traveling wave etc. are sent to the traveling wave fault location platform. Cloud computing platform can quickly call related data and scheduled algorithms to achieve traveling wave fault location. In the cloud computing platform layer, the following algorithms are scheduled, such as judging the section connecting point, multi-objective optimal TWU configuration, fault section determination, fault information fusion, and fault location. Users can check all the data needed anywhere and anytime in the user layer.

\subsection{Analysis the relationship between topology structure and shortest transmission path}

For the double-terminal traveling wave fault location method, as seen in Eq. (1), in order to correctly calculate the

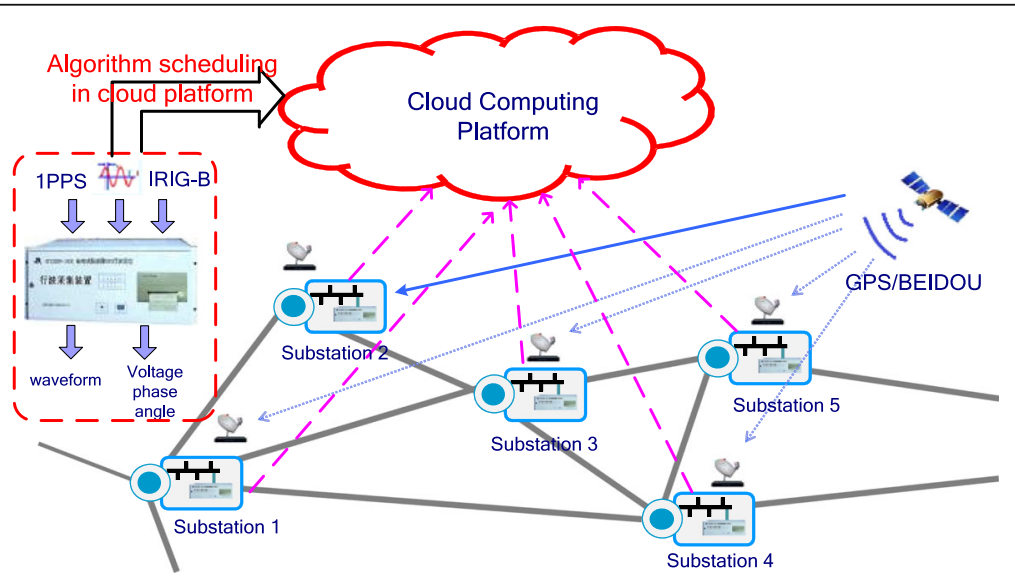

Fig. 1 Multi-terminal traveling wave fault location network based on cloud computing platform 


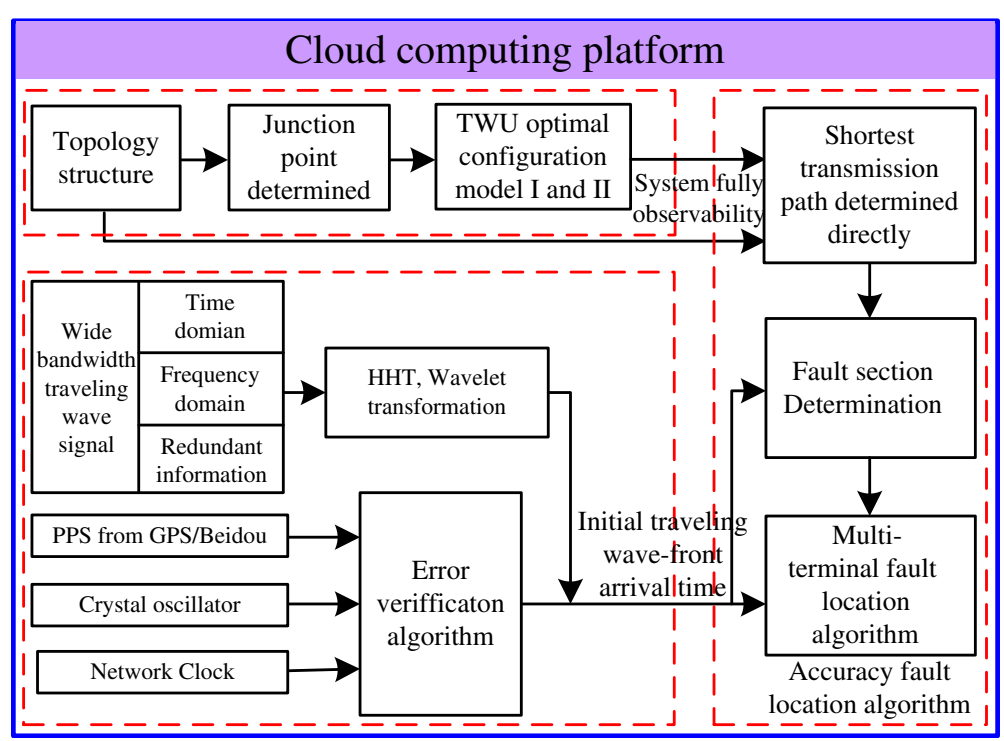

Fig. 2 Cloud computing for traveling wave fault location

fault position, the initial traveling wave arrival times $t_{M} 、 t_{N}$ and the shortest transmission path $\mathrm{L}_{\mathrm{MN}}$ must be known.

$$
d_{M}=\left[v\left(t_{M}-t_{N}\right)+l_{M N}\right] / 2
$$

For a single transmission line $\mathrm{M}-\mathrm{N}, \mathrm{L}_{\mathrm{MN}}$ is the length of $\mathrm{M}-\mathrm{N}$. However, in a complicated network, $\mathrm{L}_{\mathrm{MN}}$ cannot be directly determined. As shown in Fig. 3, TWU is not installed in substations $\mathrm{M}$ and $\mathrm{N}$. Thus, the initial traveling wave-front will pass through both ends of the substations and then transmit to the TWU installed in the distant substations $\mathrm{X}$ and $\mathrm{Y}$ (called detection point in the paper). $\mathrm{L}_{\mathrm{XY}}$ must satisfy the following condition: $\mathrm{L}_{\mathrm{XY}}=\mathrm{L}_{\mathrm{fX}}+\mathrm{L}_{\mathrm{fY}}$, where, $\mathrm{L}_{\mathrm{fX}}$ and $\mathrm{L}_{\mathrm{fY}}$ represent the shortest transmission path from the fault point $\mathrm{f}$ to the detection points $\mathrm{X}$ and $\mathrm{Y}$, respectively. $\mathrm{L}_{\mathrm{fX}}$ 、 $\mathrm{L}_{\mathrm{fY}}$ cannot be determined directly because of the existence of the loop. When a fault occurs in section $\mathrm{O}_{2} \mathrm{~N}$, the shortest transmission path is $\mathrm{L}_{\mathrm{fX}}=\mathrm{k}_{1}$. While for a fault

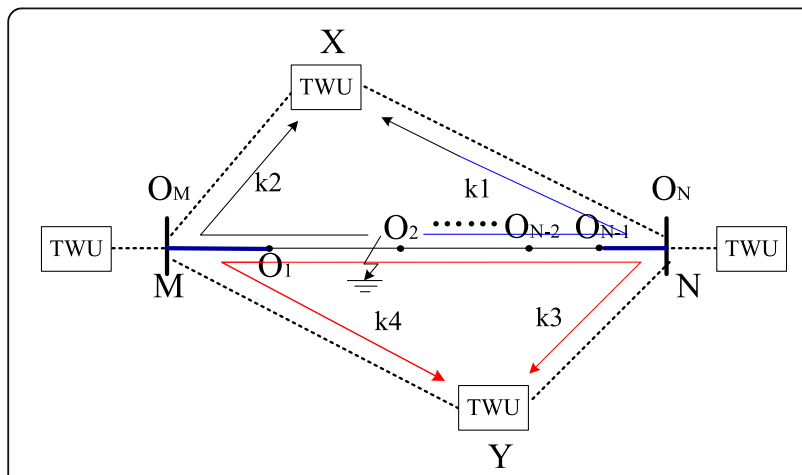

Fig. 3 The shortest path matching scheme in the complex network occurring in section $\mathrm{MO}_{2}$, the shortest transmission path is $\mathrm{L}_{\mathrm{fX}}=\mathrm{k}_{2}$. Thus, in the loop, the shortest transmission path of the initial traveling wave-front varies with the fault section.

In addition, if the fault occurred within section $\mathrm{O}_{\mathrm{i}} \mathrm{N}$, the initial traveling wave-front transmits to the detection point $\mathrm{X}$ via path $\mathrm{k}_{1}$ and to another detection point $\mathrm{Y}$ via the path $\mathrm{k}_{3}$. Consequently, the calculated fault position is substation $\mathrm{N}$, thus the fault location method is failed due to the blind spot.

In summary, the following conclusions can be drawn:

(1) The transmission path for initial traveling wave is determined by network topology structure, and varies with difference fault section.

(2)In complicated network, based on double-terminal traveling wave fault location method, at least a pair of TWU in X and Y must be installed. The corresponding shortest transmission path $\mathrm{L}_{\mathrm{fX}}$ and $\mathrm{L}_{\mathrm{fY}}$ must from $\mathrm{f}$ via substation $\mathrm{M}$ or $\mathrm{N}$ to the TWU located at $\mathrm{X}$ or $\mathrm{Y}$. In this condition, the complicated network has full observability

\subsection{Multi-objective optimal TWU configuration method 2.3.1 Searching section connecting point}

In Fig. 3, when a fault occurs at $\mathrm{f}$ on line $\mathrm{M}-\mathrm{N}$, the shortest transmission path of the initial traveling wavefront must satisfy the following equation:

$$
L_{f X}=\min \left\{L_{f N}+L_{N X}, L_{f M}+L_{M X}\right\}
$$


The key point of the Eq. (2) is on the determination of whether the initial traveling wave-front will pass through via fault starting point $\mathrm{M}$ or $\mathrm{N}$, which must meet the following relationships:

If the topology structure of any fault line $\mathrm{M}-\mathrm{N}$ and the third detection point $\mathrm{X}$ satisfy the following equation:

$$
L_{M X} \leq L_{N X} \leq L_{M N}+L_{M X}
$$

the fault line can be divided into some sections according to:

$$
l_{O_{i} M}=\frac{l_{M N}}{2}+\left(\frac{l_{N X}-l_{M X}}{2}\right)
$$

where $\mathrm{O}_{\mathrm{i}}$ is the section connecting point of the line $\mathrm{M}-\mathrm{N}$ corresponding to the detection point $\mathrm{X}$. It can divide the line $\mathrm{M}-\mathrm{N}$ into several sections: $\left[\mathrm{O}_{\mathrm{M}}, \mathrm{O}_{1}\right]$, $\left[\mathrm{O}_{1}, \mathrm{O}_{2}\right], \ldots \ldots,\left[\mathrm{O}_{\mathrm{N}-2}, \mathrm{O}_{\mathrm{N}-1}\right],\left[\mathrm{O}_{\mathrm{N}-1}, \mathrm{O}_{\mathrm{N}}\right]$. For a fault within section $\left[\mathrm{O}_{\mathrm{i}-1}, \mathrm{O}_{\mathrm{i}}\right]$, the shortest transmission path of the initial traveling wave-front can be uniquely determined.

Considering two special conditions:

(1) When $l_{N X}=l_{M N}+l_{M X}, l_{M O_{i}}=\mathrm{l}_{M N}$. The section connecting point $\mathrm{O}_{\mathrm{i}}$ is located at substation $\mathrm{N}$. If a fault occurs within section $\left[\mathrm{O}_{\mathrm{N}-1}, \mathrm{O}_{\mathrm{N}}\right]$, the shortest transmission paths are all via substation $M$. The area $\left[\mathrm{O}_{\mathrm{N}-1}, \mathrm{O}_{\mathrm{N}}\right]$ is a fault location blind spot, as seen in Fig. 3.

(2) When $l_{M X}=l_{M N}+l_{N X}, l_{M O_{i}}=0$. The section connecting point $\mathrm{O}_{\mathrm{i}}$ is located at substation $\mathrm{M}$. If a fault occurs within section $\left[\mathrm{O}_{\mathrm{M}}, \mathrm{O}_{1}\right]$, the shortest transmission paths are all via substation $\mathrm{N}$. The area $\left[\mathrm{O}_{\mathrm{M}}, \mathrm{O}_{1}\right]$ is thus a fault location blind spot, as seen in Fig. 3.

Thus, the area $\left[\mathrm{O}_{1}, \mathrm{O}_{\mathrm{N}-1}\right]$ is observable, but the areas $\left[\mathrm{O}_{\mathrm{M}}, \mathrm{O}_{1}\right] 、\left[\mathrm{O}_{\mathrm{N}-1}, \mathrm{O}_{\mathrm{N}}\right]$ are the blind areas. Therefore, if a line is fully observable, the section connecting point should both have $\mathrm{O}_{\mathrm{N}}$ and $\mathrm{O}_{\mathrm{M}}$.

\subsubsection{Multi-objective optimal configuration method}

Based on the above analysis, TWUs can be optimally configured by setting up multi-objective models.

The arrays for the initial traveling wave-front transmission path are set up first. For any sections in the fault line $\mathrm{M}-\mathrm{N}$, arrays $\left[\mathrm{G}_{\mathrm{M}}\right]$ or $\left[\mathrm{G}_{\mathrm{N}}\right]$ stand for the initial traveling wave transmission path via starting fault point $\mathrm{M}$ or $\mathrm{N}$ to the remote TWU. Substation array $\left[\mathrm{T}_{\mathrm{i}}\right]$ is then set up, indicating substations with installed TWU. Binary coding for $\left[G_{M}\right],\left[G_{N}\right]$ and $\left[\mathrm{T}_{\mathrm{i}}\right]$ are listed in Tables 1 and 2.

If the whole network is fully observable $[18,19]$, array $[G]$ and $[\mathrm{T}]$ must meet the following equation:

$$
\left\{\begin{array}{l}
1 \leq \sum_{k=1}^{N} T_{i} G_{X} \leq \sum_{k=1}^{N} T_{i}-1 \\
1 \leq \sum_{k=1}^{N} T_{i} G_{Y} \leq \sum_{k=1}^{N} T_{i}-1
\end{array}\right.
$$

where $\mathrm{N}$ stands for the total number of substation.

Considering minimum number of substations with installed TWU and network full observability, the multi-objective optimal configuration model I can be easily set up:

$$
\begin{aligned}
& \min \quad K=\sum_{i=1}^{n} T_{i} \\
& \text { s.t. } 1<\mathrm{X}<\mathrm{Y}_{N}<\mathrm{N} \\
& \sum_{k=1}^{N} T_{i} G_{X} \times \sum_{k=1}^{N} T_{i} G_{Y} \geq 1 \\
& L_{f X}=\min \left\{L_{f N}+L_{N X}, L_{f M}+L_{M X}\right\}
\end{aligned}
$$

At the same time, if there are blind spots in the network, their number is minimal and they remain totally the same before and after optimal TWUs configuration. Thus, the multi-objective optimal configuration model II can be set up:

$$
\begin{aligned}
& \min K=\sum_{i=1}^{n} T_{i} \\
& \text { s.t. } \max \left(\max O_{i}-\min O_{1}\right)
\end{aligned}
$$

Multi-objective optimal configuration model I and II are equal. The more constraints they have, the easier the problem is solved.

It is worth noting that some principles must be satisfied for special conditions.

(1)Because blind area is located at the terminal of

\begin{tabular}{|c|c|c|}
\hline Array & $\begin{array}{l}\text { Binary } \\
\text { code }\end{array}$ & Explanation \\
\hline \multirow[t]{2}{*}[G_{M}]{} & 1 & $\begin{array}{l}\text { Initial traveling wave transmission path via starting } \\
\text { fault point } M \text { to remote TWU }\end{array}$ \\
\hline & 0 & $\begin{array}{l}\text { Initial traveling wave transmission path via starting } \\
\text { fault point } \mathrm{N} \text { to remote TWU }\end{array}$ \\
\hline \multirow[t]{2}{*}[G_{N}]{} & 0 & $\begin{array}{l}\text { Initial traveling wave transmission path via starting } \\
\text { fault point } M \text { to remote TWU }\end{array}$ \\
\hline & 1 & $\begin{array}{l}\text { Initial traveling wave transmission path via starting } \\
\text { fault point } \mathrm{N} \text { to remote TWU }\end{array}$ \\
\hline
\end{tabular}
the lines, such as $\left[\mathrm{O}_{\mathrm{M}}, \mathrm{O}_{1}\right]$ and $\left[\mathrm{O}_{\mathrm{N}-1}, \mathrm{O}_{\mathrm{N}}\right]$ in Fig. 3, it is necessary to installed extra TWU in substation $\mathrm{M}$ and $\mathrm{N}$. It can use single-terminal fault location principle to locate the fault occurs at the blind area.

(2)For local center substation, if the number of out and in feeders is more than 4, TWU shall be installed.

Table 1 Initial traveling wave-front transmission path array [G] 
Table 2 Substation array [T]

\begin{tabular}{lll}
\hline Array & Binary code & Explanation \\
\hline$\left[\Gamma_{i}\right]$ & 1 & Substation $\mathrm{i}$ installed TWU \\
& 0 & Substation i without TWU
\end{tabular}

(3) The terminal substations must install TWU.

\subsection{Multi-terminal traveling wave fault location method}

\subsubsection{Determination of fault section}

Due to the unknown fault position, it is necessary to judge the fault section based on the traveling wavefront signal recorded in the detection point.

In the complicated loop, there might be one or more section connecting points $\mathrm{O}_{\mathrm{i}}$. Taking the section $\left(\mathrm{O}_{\mathrm{i}-1}\right.$, $\mathrm{O}_{\mathrm{i}}$ ) as a reference, it can divide all the substations with TWU installed into two Detection Arrays $[\mathrm{I}]_{\mathrm{N}}$ and $[\mathrm{I}]_{\mathrm{M}}$. Thus, Initial traveling wave-front arrival times recorded by the substations from Detection Arrays $[\mathrm{I}]_{\mathrm{N}}$ and $[\mathrm{I}]_{\mathrm{M}}$ form Computation Time Arrays $[t]_{N}$ and $[t]_{M}$. Because of the temporal correlation, the transmission times that initial traveling wave-front passes through the starting point $\mathrm{M}$ or $\mathrm{N}$ to any substation in the Detection Arrays can be calculated as follows:

$$
\left\{\begin{array}{cc}
T_{M Y}=\frac{L_{N X}}{v_{N X}} & \forall X \in[\mathrm{I}]_{\mathrm{N}} \\
T_{M Y}=\frac{L_{M Y}}{v_{M Y}} & \forall Y \in[\mathrm{I}]_{\mathrm{M}}
\end{array}\right.
$$

where $L_{N X}$ and $L_{M Y}$ can be obtained from the topology structure, and $\mathrm{v}_{\mathrm{NX}}$ and $\mathrm{v}_{\mathrm{MY}}$ are the univariate functions of the distance that can be calculated online ${ }^{[23]}$.

If initial traveling wave-front arrival times from Computation Time Array $[t]_{N}$ and $[t]_{M}$ satisfy Eq. (9), it means that the fault point is within section $\left(\mathrm{O}_{\mathrm{i}-1}, \mathrm{O}_{\mathrm{i}}\right)$. Thus the shortest transmission path can be uniquely determined.

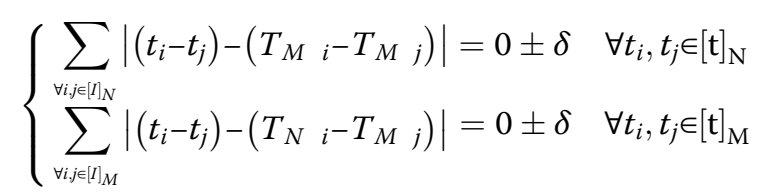

where $t_{i}$ and $t_{j}$ are the initial traveling wave arrival times recorded by the substations from Detection Arrays $[\mathrm{I}]_{\mathrm{N}}$ and $[\mathrm{I}]_{\mathrm{M}}$, respectively. Both $\mathrm{T}_{\mathrm{iM}}$ and $\mathrm{T}_{\mathrm{iN}}$ can be calculated using Eq. (8). Considering the errors caused by different influence factors, a margin $\delta$ is taking into consideration in Eq. (9), and its nominal value is 0.5us.

\subsubsection{Multi-terminal fault location algorithm}

After determining the fault section, the exact fault point can be easily calculated as:

$$
\begin{aligned}
& d_{f i}=\frac{v\left(t_{i}-t_{j}\right)+L^{\mathrm{min}}}{2} \\
& d_{f M}=d_{f i}-l_{M i}
\end{aligned}
$$

where $t_{i}, t_{j}$ are from Computation Time Array $[t]_{N}$ and $[t]_{M}$ respectively, and $L_{i j}^{m i n}$ is the shortest transmission line between substations $i$ and $j$.

Converting the fault distance $\mathrm{d}_{\mathrm{fi}}$ to one of the terminals $M$ of the fault line, $d_{f M}$ can be calculated by Eq. (11), where $l_{M i}$ is the distance between substation $i$ with installed TWU and the reference terminal M.

Any two substations from Detection Arrays $[\mathrm{I}]_{\mathrm{N}}$ and $[\mathrm{I}]_{\mathrm{M}}$ can calculate the fault location $\mathrm{d}_{\mathrm{fi}}$ and $\mathrm{d}_{\mathrm{fM}}$, and then fuse all the calculated $d_{\mathrm{fM}}$ using weightings as:

$$
d_{m}=\frac{\sum_{i} \sum_{j} W_{i j} \times d_{f M}}{\sum_{i} \sum_{j} W_{i j}}
$$

The principle for setting the weights is dependent on the fault line. The substations, which are joined by the fault line directly, has its weight set to 1 , and the rest of the substations have their weights set to $1 /(n+1)$, where $\mathrm{n}$ is the substation sequence numbers passing the shortest path from the fault line.

\section{Results and simulation}

\subsection{Simulation model}

To valid the correctness and applicability of the proposed method, large numbers of simulations have been carried out using PSCAD/EMTDC. The simulation system is shown in Fig. 4(a), and the related parameters are shown in Table 4 in Appendix A.

\subsection{Realization for the optimal TWU configuration 3.2.1 Step 1: searching section connecting points}

Figure 4 shows the IEEE 30-bus testing system, which has 41 lines and 30 substations. Assuming each substation installs TWU, the section connecting points and their corresponding substations can be calculated based on Eqs. (3) and (4) using Dijkstra. The calculation results are shown in Table 5 in Appendix A.

From Table 5, it can be seen that the whole network is fully observable because the section connecting point both have $\mathrm{O}_{\mathrm{N}}$ and $\mathrm{O}_{\mathrm{M}}$

\subsubsection{Step 2: multi-objective optimal configuration realization}

Based on the section connecting points and their corresponding substations, a matrix $\left[\mathrm{H}_{\mathrm{L} \times 2}\right](1 \leq \mathrm{L} \leq 41)$ can be obtained. The first column is the minimum section connecting point $\mathrm{O}_{\mathrm{M}}$, while the second column is the 

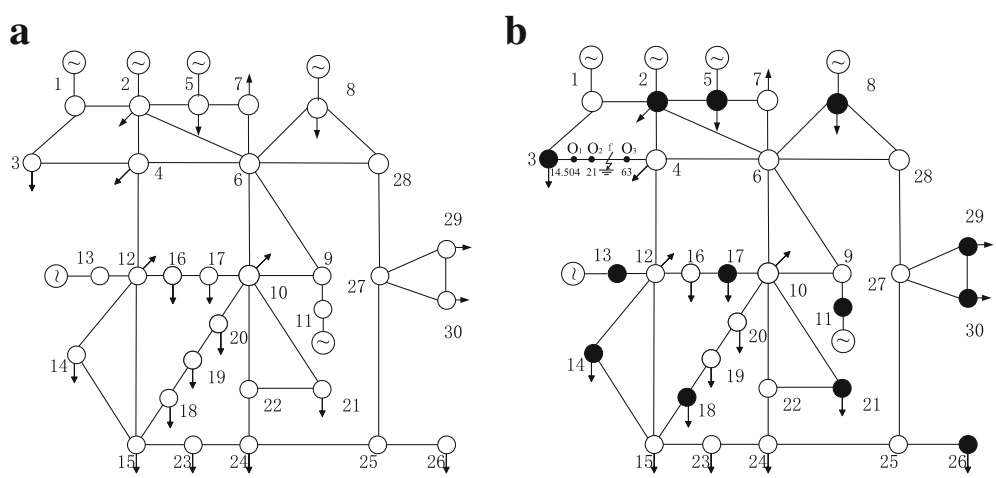

Fig. 4 The IEEE 30-bus testing system and its optimal TWU configuration. a IEEE 30-bus testing system. b TWUs optimal configuration

maximum section connecting point $\mathrm{O}_{\mathrm{N}}$. The matrix $\left[\mathrm{H}_{\mathrm{L} \times 2}\right]$ is shown in Table 6 in Appendix A.

For each row, if the number of section connecting point $\left[\mathrm{O}_{\mathrm{M}}\right]_{\mathrm{L}} /\left[\mathrm{O}_{\mathrm{N}}\right]_{\mathrm{L}}$ is 1 , the substation must install TWU, and matrix [A] is obtained. For the IEEE 30-bus testing system, matrix $[\mathrm{A}]$ is as follows:

$$
[\mathrm{A}]=[3,8,11,13,14,21,26,29,30]
$$

For other rows, the minimum sharing set is searched and $[\mathrm{A}]_{\mathrm{M}}$ and $[\mathrm{A}]_{\mathrm{N}}$ are formed as:

$$
\begin{aligned}
& {[\mathrm{A}]_{\mathrm{M}}=[5,7],[16,17],[10,18,19,20]} \\
& {[\mathrm{A}]_{\mathrm{N}}=[1,2],[15,18,19]}
\end{aligned}
$$

The minimum sharing sets between $[\mathrm{A}]_{\mathrm{M}}$ and $[\mathrm{A}]_{\mathrm{N}}$ are then searched, i.e. [5,7], [16,17], [1,2], [18,19] in this case. One substation in each of the matrix is chosen to install TWU.

For substations in the matrix [1,2], [5,7], [16,17], $[18,19]$, it is desirable to install TWU in local center substations 2, 5, 17 and 18 .

Finally, the optimal TWU configuration is in the following 13 substations: 2,3,5,8,11,13,14,17,18,21,26,29,30, as shown in Fig. 4(b).

\subsection{Realization for the multi-terminal traveling wave fault location}

\subsubsection{Step 3: fault section judgment}

Assuming the fault occurred at $45 \mathrm{kM}$ in line 3-4 from substation 3, the initial traveling wave-front arrival times are recorded in Table 3. The fault section is then calculated using Eqs. (8) and (9), and the result is $\left(\mathrm{O}_{2}, \mathrm{O}_{3}\right)$.

\subsubsection{Step 4: calculation of the fault position}

Detection arrays for fault line 3-4 are:

$$
\begin{aligned}
& {[\mathrm{I}]_{3}=[3]} \\
& {[\mathrm{I}]_{4}=[2,4,5,8,11,13,14,17,18,21,26,29,30]}
\end{aligned}
$$

First, it calculates the fault distance $\mathrm{d}_{\mathrm{fi}}$, and then converts the fault distance to the reference terminal 3 of the fault line: $d_{f 3}$. Weights are applied for each substation installed with TWU, and the final fault location can be calculated using Eq. (12). Thus, the final fault point is located at $45.078 \mathrm{kM}$ from substation 3 , and the absolute error is $0.078 \mathrm{kM}$.

\section{Conclusion}

(1) A multi-objective optimal TWU configuration method is proposed based on network full observability and minimum number of TWU, which significantly decrease the one-off investment.

(2) A novel traveling wave fault location method is presented in the paper. The method can directly match the shortest transmission path without the need for simplifying complicated loops and matching steps, and is immune to fault position and topology structure. It can be easily realized and has strong feasibility.

(3) The proposed method can achieve precise fault location with only limited numbers of TWU and can effectively improve the economics and practice for the multi-terminal traveling wave fault location system.

Table 3 Initial traveling wave arrival times recorded in substations installed TWU

\begin{tabular}{lrrr}
\hline $\begin{array}{c}\text { TWU } \\
\text { time/us }\end{array}$ & $\begin{array}{c}\text { Initial traveling wave arrival } \\
\text { time/us }\end{array}$ & $\begin{array}{l}\text { Initial traveling wave arrival } \\
\text { time/us }\end{array}$ \\
\hline 2 & 1071.92 & 17 & 1082.19 \\
3 & 154.10 & 18 & 1267.12 \\
5 & 1246.58 & 21 & 1821.92 \\
8 & 1243.15 & 26 & 2845.89 \\
11 & 1376.71 & 29 & 2452.05 \\
13 & 277.40 & 30 & 1715.75 \\
14 & 993.15 & & \\
\hline
\end{tabular}




\section{Appendix A}

Table 4 Transmission-line lengths of the IEEE 30-bus test system

\begin{tabular}{|c|c|c|c|c|c|}
\hline Line & Length/kM & Line & Length/kM & Line & Length/kM \\
\hline $1-2$ & 42 & $8-28$ & 193 & $16-17$ & 155 \\
\hline $1-3$ & 274 & $9-10$ & 96 & $18-19$ & 230 \\
\hline $2-4$ & 278 & $9-11$ & 61 & 19-20 & 187 \\
\hline $2-5$ & 51 & $10-17$ & 116 & $21-22$ & 67 \\
\hline $2-6$ & 241 & $10-20$ & 65 & $22-24$ & 155 \\
\hline $3-4$ & 80 & $10-21$ & 220 & $23-24$ & 138 \\
\hline $4-6$ & 112 & $10-22$ & 204 & $24-25$ & 240 \\
\hline $4-12$ & 27 & $12-13$ & 19 & $25-26$ & 119 \\
\hline $5-7$ & 173 & $12-14$ & 228 & $25-27$ & 234 \\
\hline $6-7$ & 31 & $12-15$ & 271 & $27-28$ & 192 \\
\hline $6-8$ & 216 & $12-16$ & 99 & $27-29$ & 238 \\
\hline $6-9$ & 194 & $14-15$ & 149 & $27-30$ & 162 \\
\hline $6-10$ & 165 & $15-18$ & 37 & 29-30 & 111 \\
\hline $6-28$ & 139 & $15-23$ & 135 & & \\
\hline
\end{tabular}

Table $\mathbf{5}$ The distribution of Junction points in the IEEE-30 bus testing system

\begin{tabular}{|c|c|c|c|c|c|c|c|c|c|c|}
\hline Line/Substation & 1 & 2 & 3 & 4 & 5 & 6 & 7 & 8 & 9 & 10 \\
\hline $1-2$ & 1.0000 & 0.0000 & 1.0000 & 0.0000 & 0.0000 & 0.0000 & 0.0000 & 0.0000 & 0.0000 & 0.0000 \\
\hline $1-3$ & 1.0000 & 1.0000 & 0.0000 & 0.0620 & 1.0000 & 0.3339 & 0.4215 & 0.3339 & 0.3339 & 0.3339 \\
\hline $2-4$ & 1.0000 & 1.0000 & 0.0755 & 0.0000 & 0.9766 & 0.2680 & 0.3543 & 0.2680 & 0.2680 & 0.2680 \\
\hline $2-5$ & 1.0000 & 1.0000 & 1.0000 & 0.8725 & 0.0000 & 0.1373 & 0.0000 & 0.1373 & 0.1373 & 0.1373 \\
\hline $2-6$ & 1.0000 & 1.0000 & 0.2427 & 0.1556 & 0.8174 & 0.0000 & 0.0996 & 0.0000 & 0.0000 & 0.0000 \\
\hline $3-4$ & 0.7875 & 0.2625 & 1.0000 & 0.0000 & 0.1813 & 0.0000 & 0.0000 & 0.0000 & 0.0000 & 0.0000 \\
\hline $4-6$ & 0.3348 & 0.3348 & 1.0000 & 1.0000 & 0.0000 & 0.0000 & 0.0000 & 0.0000 & 0.0000 & 0.0000 \\
\hline $4-12$ & 1.0000 & 1.0000 & 1.0000 & 1.0000 & 1.0000 & 1.0000 & 1.0000 & 1.0000 & 1.0000 & 1.0000 \\
\hline $5-7$ & 1.0000 & 1.0000 & 0.0838 & 0.0000 & 1.0000 & 0.0000 & 0.0000 & 0.0000 & 0.0000 & 0.0000 \\
\hline $6-7$ & 0.2258 & 0.2258 & 1.0000 & 1.0000 & 0.0000 & 1.0000 & 0.0000 & 1.0000 & 1.0000 & 1.0000 \\
\hline $6-8$ & 1.0000 & 1.0000 & 1.0000 & 1.0000 & 1.0000 & 1.0000 & 1.0000 & 0.0000 & 1.0000 & 1.0000 \\
\hline $6-9$ & 1.0000 & 1.0000 & 1.0000 & 1.0000 & 1.0000 & 1.0000 & 1.0000 & 1.0000 & 0.0000 & 0.3222 \\
\hline 6-10 & 1.0000 & 1.0000 & 1.0000 & 1.0000 & 1.0000 & 1.0000 & 1.0000 & 1.0000 & 0.2030 & 0.0000 \\
\hline $6-28$ & 1.0000 & 1.0000 & 1.0000 & 1.0000 & 1.0000 & 1.0000 & 1.0000 & 0.4173 & 1.0000 & 1.0000 \\
\hline $8-28$ & 0.3005 & 0.3005 & 0.3005 & 0.3005 & 0.3005 & 0.3005 & 0.3005 & 1.0000 & 0.3005 & 0.3005 \\
\hline 9-10 & 0.3490 & 0.3490 & 0.3490 & 0.3490 & 0.3490 & 0.3490 & 0.3490 & 0.3490 & 1.0000 & 0.0000 \\
\hline 9-11 & 1.0000 & 1.0000 & 1.0000 & 1.0000 & 1.0000 & 1.0000 & 1.0000 & 1.0000 & 1.0000 & 1.0000 \\
\hline 10-17 & 1.0000 & 1.0000 & 0.5172 & 0.5172 & 1.0000 & 1.0000 & 1.0000 & 1.0000 & 1.0000 & 1.0000 \\
\hline 10-20 & 1.0000 & 1.0000 & 1.0000 & 1.0000 & 1.0000 & 1.0000 & 1.0000 & 1.0000 & 1.0000 & 1.0000 \\
\hline $10-21$ & 1.0000 & 1.0000 & 1.0000 & 1.0000 & 1.0000 & 1.0000 & 1.0000 & 1.0000 & 1.0000 & 1.0000 \\
\hline $10-22$ & 1.0000 & 1.0000 & 1.0000 & 1.0000 & 1.0000 & 1.0000 & 1.0000 & 1.0000 & 1.0000 & 1.0000 \\
\hline $12-13$ & 1.0000 & 1.0000 & 1.0000 & 1.0000 & 1.0000 & 1.0000 & 1.0000 & 1.0000 & 1.0000 & 1.0000 \\
\hline $12-14$ & 1.0000 & 1.0000 & 1.0000 & 1.0000 & 1.0000 & 1.0000 & 1.0000 & 1.0000 & 1.0000 & 1.0000 \\
\hline
\end{tabular}


Table 5 The distribution of Junction points in the IEEE-30 bus testing system (Continued)

\begin{tabular}{|c|c|c|c|c|c|c|c|c|c|c|}
\hline $12-15$ & 1.0000 & 1.0000 & 1.0000 & 1.0000 & 1.0000 & 1.0000 & 1.0000 & 1.0000 & 1.0000 & 0.8967 \\
\hline $12-16$ & 1.0000 & 1.0000 & 1.0000 & 1.0000 & 1.0000 & 1.0000 & 1.0000 & 1.0000 & 0.6717 & 0.3333 \\
\hline 14-15 & 0.6443 & 0.6443 & 0.6443 & 0.6443 & 0.6443 & 0.6443 & 0.6443 & 0.6443 & 0.6443 & 0.4564 \\
\hline $15-18$ & 1.0000 & 1.0000 & 1.0000 & 1.0000 & 1.0000 & 1.0000 & 1.0000 & 1.0000 & 0.1486 & 0.0000 \\
\hline $15-23$ & 1.0000 & 1.0000 & 1.0000 & 1.0000 & 1.0000 & 1.0000 & 1.0000 & 1.0000 & 0.4593 & 0.4185 \\
\hline $16-17$ & 0.8806 & 0.8806 & 1.0000 & 1.0000 & 0.6387 & 0.6387 & 0.6387 & 0.6387 & 0.0000 & 0.0000 \\
\hline 18-19 & 0.5978 & 0.5978 & 0.9217 & 0.9217 & 0.4348 & 0.4348 & 0.4348 & 0.4348 & 0.0000 & 0.0000 \\
\hline 19-20 & 0.0000 & 0.0000 & 0.0000 & 0.0000 & 0.0000 & 0.0000 & 0.0000 & 0.0000 & 0.0000 & 0.0000 \\
\hline $21-22$ & 0.3806 & 0.3806 & 0.3806 & 0.3806 & 0.3806 & 0.3806 & 0.3806 & 0.3806 & 0.3806 & 0.3806 \\
\hline $22-24$ & 1.0000 & 1.0000 & 0.7903 & 0.7903 & 1.0000 & 1.0000 & 1.0000 & 1.0000 & 1.0000 & 1.0000 \\
\hline $23-24$ & 0.6957 & 0.6957 & 1.0000 & 1.0000 & 0.4239 & 0.4239 & 0.4239 & 0.4239 & 0.0000 & 0.0000 \\
\hline $24-25$ & 0.5854 & 0.5854 & 0.7208 & 0.7208 & 0.5854 & 0.5854 & 0.5854 & 0.2479 & 1.0000 & 1.0000 \\
\hline $25-26$ & 1.0000 & 1.0000 & 1.0000 & 1.0000 & 1.0000 & 1.0000 & 1.0000 & 1.0000 & 1.0000 & 1.0000 \\
\hline $25-27$ & 0.0000 & 0.0000 & 0.0000 & 0.0000 & 0.0000 & 0.0000 & 0.0000 & 0.0000 & 0.1368 & 0.2799 \\
\hline $27-28$ & 0.0000 & 0.0000 & 0.0000 & 0.0000 & 0.0000 & 0.0000 & 0.0000 & 0.0000 & 0.0000 & 0.0000 \\
\hline $27-29$ & 1.0000 & 1.0000 & 1.0000 & 1.0000 & 1.0000 & 1.0000 & 1.0000 & 1.0000 & 1.0000 & 1.0000 \\
\hline $27-30$ & 1.0000 & 1.0000 & 1.0000 & 1.0000 & 1.0000 & 1.0000 & 1.0000 & 1.0000 & 1.0000 & 1.0000 \\
\hline 29-30 & 0.1577 & 0.1577 & 0.1577 & 0.1577 & 0.1577 & 0.1577 & 0.1577 & 0.1577 & 0.1577 & 0.1577 \\
\hline Line/Substation & 11 & 12 & 13 & 14 & 15 & 16 & 17 & 18 & 19 & 20 \\
\hline $1-2$ & 0.0000 & 0.0000 & 0.0000 & 0.0000 & 0.0000 & 0.0000 & 0.0000 & 0.0000 & 0.0000 & 0.0000 \\
\hline $1-3$ & 0.3339 & 0.0620 & 0.0620 & 0.0620 & 0.0620 & 0.0620 & 0.1296 & 0.0620 & 0.3339 & 0.3339 \\
\hline $2-4$ & 0.2680 & 0.0000 & 0.0000 & 0.0000 & 0.0000 & 0.0000 & 0.0665 & 0.0000 & 0.2680 & 0.2680 \\
\hline $2-5$ & 0.1373 & 0.8725 & 0.8725 & 0.8725 & 0.8725 & 0.8725 & 0.1373 & 0.8725 & 0.1373 & 0.1373 \\
\hline $2-6$ & 0.0000 & 0.1556 & 0.1556 & 0.1556 & 0.1556 & 0.1556 & 0.0000 & 0.1556 & 0.0000 & 0.0000 \\
\hline $3-4$ & 0.0000 & 0.0000 & 0.0000 & 0.0000 & 0.0000 & 0.0000 & 0.0000 & 0.0000 & 0.0000 & 0.0000 \\
\hline $4-6$ & 0.0000 & 1.0000 & 1.0000 & 1.0000 & 1.0000 & 1.0000 & 0.5000 & 1.0000 & 0.0000 & 0.0000 \\
\hline $4-12$ & 1.0000 & 0.0000 & 0.0000 & 0.0000 & 0.0000 & 0.0000 & 0.0000 & 0.0000 & 0.6667 & 1.0000 \\
\hline $5-7$ & 0.0000 & 0.0000 & 0.0000 & 0.0000 & 0.0000 & 0.0000 & 0.0000 & 0.0000 & 0.0000 & 0.0000 \\
\hline $6-7$ & 1.0000 & 1.0000 & 1.0000 & 1.0000 & 1.0000 & 1.0000 & 1.0000 & 1.0000 & 1.0000 & 1.0000 \\
\hline $6-8$ & 1.0000 & 1.0000 & 1.0000 & 1.0000 & 1.0000 & 1.0000 & 1.0000 & 1.0000 & 1.0000 & 1.0000 \\
\hline $6-9$ & 0.0000 & 1.0000 & 1.0000 & 1.0000 & 1.0000 & 0.8325 & 0.3222 & 0.8376 & 0.3222 & 0.3222 \\
\hline $6-10$ & 0.2030 & 1.0000 & 1.0000 & 1.0000 & 0.8303 & 0.6000 & 0.0000 & 0.6061 & 0.0000 & 0.0000 \\
\hline $6-28$ & 1.0000 & 1.0000 & 1.0000 & 1.0000 & 1.0000 & 1.0000 & 1.0000 & 1.0000 & 1.0000 & 1.0000 \\
\hline $8-28$ & 0.3005 & 0.3005 & 0.3005 & 0.3005 & 0.3005 & 0.3005 & 0.3005 & 0.3005 & 0.3005 & 0.3005 \\
\hline 9-10 & 1.0000 & 0.3490 & 0.3490 & 0.3490 & 0.0573 & 0.0000 & 0.0000 & 0.0000 & 0.0000 & 0.0000 \\
\hline 9-11 & 0.0000 & 1.0000 & 1.0000 & 1.0000 & 1.0000 & 1.0000 & 1.0000 & 1.0000 & 1.0000 & 1.0000 \\
\hline 10-17 & 1.0000 & 0.2845 & 0.2845 & 0.2845 & 0.5259 & 0.0000 & 0.0000 & 0.8448 & 1.0000 & 1.0000 \\
\hline 10-20 & 1.0000 & 1.0000 & 1.0000 & 1.0000 & 0.0000 & 1.0000 & 1.0000 & 0.0000 & 0.0000 & 0.0000 \\
\hline $10-21$ & 1.0000 & 1.0000 & 1.0000 & 0.7545 & 0.4455 & 1.0000 & 1.0000 & 0.6136 & 1.0000 & 1.0000 \\
\hline $10-22$ & 1.0000 & 1.0000 & 1.0000 & 0.6103 & 0.2770 & 1.0000 & 1.0000 & 0.4583 & 1.0000 & 1.0000 \\
\hline $12-13$ & 1.0000 & 1.0000 & 0.0000 & 1.0000 & 1.0000 & 1.0000 & 1.0000 & 1.0000 & 1.0000 & 1.0000 \\
\hline $12-14$ & 1.0000 & 1.0000 & 1.0000 & 0.0000 & 0.2325 & 1.0000 & 1.0000 & 0.2325 & 0.2325 & 1.0000 \\
\hline $12-15$ & 1.0000 & 1.0000 & 1.0000 & 0.3542 & 0.0000 & 1.0000 & 1.0000 & 0.0000 & 0.0000 & 0.6568 \\
\hline $12-16$ & 0.6717 & 1.0000 & 1.0000 & 1.0000 & 1.0000 & 0.0000 & 0.0000 & 1.0000 & 0.4242 & 0.3333 \\
\hline 14-15 & 0.6443 & 0.6443 & 0.6443 & 1.0000 & 0.0000 & 0.6443 & 0.6443 & 0.0000 & 0.0000 & 0.0201 \\
\hline
\end{tabular}


Table 5 The distribution of Junction points in the IEEE-30 bus testing system (Continued)

\begin{tabular}{|c|c|c|c|c|c|c|c|c|c|c|}
\hline $15-18$ & 0.1486 & 1.0000 & 1.0000 & 1.0000 & 1.0000 & 1.0000 & 1.0000 & 0.0000 & 0.0000 & 0.0000 \\
\hline $15-23$ & 0.4593 & 1.0000 & 1.0000 & 1.0000 & 1.0000 & 1.0000 & 0.8259 & 1.0000 & 1.0000 & 0.9000 \\
\hline $16-17$ & 0.0000 & 1.0000 & 1.0000 & 1.0000 & 1.0000 & 1.0000 & 0.0000 & 1.0000 & 0.0000 & 0.0000 \\
\hline 18-19 & 0.0000 & 1.0000 & 1.0000 & 1.0000 & 1.0000 & 0.7522 & 0.0783 & 1.0000 & 0.0000 & 0.0000 \\
\hline 19-20 & 0.0000 & 0.0481 & 0.0481 & 0.9840 & 1.0000 & 0.0000 & 0.0000 & 1.0000 & 1.0000 & 0.0000 \\
\hline $21-22$ & 0.3806 & 0.3806 & 0.3806 & 0.0000 & 0.0000 & 0.3806 & 0.3806 & 0.0000 & 0.3806 & 0.3806 \\
\hline $22-24$ & 1.0000 & 0.6161 & 0.6161 & 0.0000 & 0.0000 & 1.0000 & 1.0000 & 0.0000 & 0.7710 & 1.0000 \\
\hline $23-24$ & 0.0000 & 1.0000 & 1.0000 & 1.0000 & 1.0000 & 0.9529 & 0.0000 & 1.0000 & 1.0000 & 0.0000 \\
\hline 24-25 & 1.0000 & 0.8333 & 0.8333 & 1.0000 & 1.0000 & 0.8604 & 1.0000 & 1.0000 & 1.0000 & 1.0000 \\
\hline $25-26$ & 1.0000 & 1.0000 & 1.0000 & 1.0000 & 1.0000 & 1.0000 & 1.0000 & 1.0000 & 1.0000 & 1.0000 \\
\hline $25-27$ & 0.1368 & 0.0000 & 0.0000 & 0.5769 & 0.9872 & 0.0000 & 0.2799 & 0.9872 & 0.4316 & 0.2799 \\
\hline $27-28$ & 0.0000 & 0.0000 & 0.0000 & 0.0000 & 0.0000 & 0.0000 & 0.0000 & 0.0000 & 0.0000 & 0.0000 \\
\hline $27-29$ & 1.0000 & 1.0000 & 1.0000 & 1.0000 & 1.0000 & 1.0000 & 1.0000 & 1.0000 & 1.0000 & 1.0000 \\
\hline $27-30$ & 1.0000 & 1.0000 & 1.0000 & 1.0000 & 1.0000 & 1.0000 & 1.0000 & 1.0000 & 1.0000 & 1.0000 \\
\hline 29-30 & 0.1577 & 0.1577 & 0.1577 & 0.1577 & 0.1577 & 0.1577 & 0.1577 & 0.1577 & 0.1577 & 0.1577 \\
\hline Line/Substation & 21 & 22 & 23 & 24 & 25 & 26 & 27 & 28 & 29 & 30 \\
\hline $1-2$ & 0.0000 & 0.0000 & 0.0000 & 0.0000 & 0.0000 & 0.0000 & 0.0000 & 0.0000 & 0.0000 & 0.0000 \\
\hline $1-3$ & 0.3339 & 0.3339 & 0.0620 & 0.2153 & 0.3339 & 0.3339 & 0.3339 & 0.3339 & 0.3339 & 0.3339 \\
\hline $2-4$ & 0.2680 & 0.2680 & 0.0000 & 0.1511 & 0.2680 & 0.2680 & 0.2680 & 0.2680 & 0.2680 & 0.2680 \\
\hline $2-5$ & 0.1373 & 0.1373 & 0.8725 & 0.1373 & 0.1373 & 0.1373 & 0.1373 & 0.1373 & 0.1373 & 0.1373 \\
\hline $2-6$ & 0.0000 & 0.0000 & 0.1556 & 0.0000 & 0.0000 & 0.0000 & 0.0000 & 0.0000 & 0.0000 & 0.0000 \\
\hline $3-4$ & 0.0000 & 0.0000 & 0.0000 & 0.0000 & 0.0000 & 0.0000 & 0.0000 & 0.0000 & 0.0000 & 0.0000 \\
\hline $4-6$ & 0.0000 & 0.0000 & 1.0000 & 0.2902 & 0.0000 & 0.0000 & 0.0000 & 0.0000 & 0.0000 & 0.0000 \\
\hline $4-12$ & 1.0000 & 1.0000 & 0.0000 & 0.0000 & 1.0000 & 1.0000 & 1.0000 & 1.0000 & 1.0000 & 1.0000 \\
\hline $5-7$ & 0.0000 & 0.0000 & 0.0000 & 0.0000 & 0.0000 & 0.0000 & 0.0000 & 0.0000 & 0.0000 & 0.0000 \\
\hline $6-7$ & 1.0000 & 1.0000 & 1.0000 & 1.0000 & 1.0000 & 1.0000 & 1.0000 & 1.0000 & 1.0000 & 1.0000 \\
\hline $6-8$ & 1.0000 & 1.0000 & 1.0000 & 1.0000 & 0.6250 & 0.6250 & 0.6250 & 0.6250 & 0.6250 & 0.6250 \\
\hline $6-9$ & 0.3222 & 0.3222 & 0.6237 & 0.3222 & 0.8351 & 0.8351 & 1.0000 & 1.0000 & 1.0000 & 1.0000 \\
\hline $6-10$ & 0.0000 & 0.0000 & 0.3545 & 0.0000 & 0.6030 & 0.6030 & 1.0000 & 1.0000 & 1.0000 & 1.0000 \\
\hline $6-28$ & 1.0000 & 1.0000 & 1.0000 & 1.0000 & 0.0000 & 0.0000 & 0.0000 & 0.0000 & 0.0000 & 0.0000 \\
\hline $8-28$ & 0.3005 & 0.3005 & 0.3005 & 0.3005 & 0.0000 & 0.0000 & 0.0000 & 0.0000 & 0.0000 & 0.0000 \\
\hline 9-10 & 0.0000 & 0.0000 & 0.0000 & 0.0000 & 0.0000 & 0.0000 & 0.3490 & 0.3490 & 0.3490 & 0.3490 \\
\hline 9-11 & 1.0000 & 1.0000 & 1.0000 & 1.0000 & 1.0000 & 1.0000 & 1.0000 & 1.0000 & 1.0000 & 1.0000 \\
\hline 10-17 & 1.0000 & 1.0000 & 1.0000 & 1.0000 & 1.0000 & 1.0000 & 1.0000 & 1.0000 & 1.0000 & 1.0000 \\
\hline 10-20 & 1.0000 & 1.0000 & 1.0000 & 1.0000 & 1.0000 & 1.0000 & 1.0000 & 1.0000 & 1.0000 & 1.0000 \\
\hline $10-21$ & 0.0000 & 0.1886 & 0.1886 & 0.1886 & 0.1886 & 0.1886 & 0.9545 & 1.0000 & 0.9545 & 0.9545 \\
\hline $10-22$ & 0.1250 & 0.0000 & 0.0000 & 0.0000 & 0.0000 & 0.0000 & 0.8260 & 1.0000 & 0.8260 & 0.8260 \\
\hline $12-13$ & 1.0000 & 1.0000 & 1.0000 & 1.0000 & 1.0000 & 1.0000 & 1.0000 & 1.0000 & 1.0000 & 1.0000 \\
\hline $12-14$ & 0.7632 & 0.6513 & 0.2325 & 0.2325 & 0.4079 & 0.4079 & 1.0000 & 1.0000 & 1.0000 & 1.0000 \\
\hline $12-15$ & 0.4465 & 0.3524 & 0.0000 & 0.0000 & 0.1476 & 0.1476 & 1.0000 & 1.0000 & 1.0000 & 1.0000 \\
\hline $12-16$ & 0.3333 & 0.3333 & 1.0000 & 0.9343 & 1.0000 & 1.0000 & 1.0000 & 1.0000 & 1.0000 & 1.0000 \\
\hline 14-15 & 0.0000 & 0.0000 & 0.0000 & 0.0000 & 0.0000 & 0.0000 & 0.6443 & 0.6443 & 0.6443 & 0.6443 \\
\hline $15-18$ & 1.0000 & 1.0000 & 1.0000 & 1.0000 & 1.0000 & 1.0000 & 1.0000 & 1.0000 & 1.0000 & 1.0000 \\
\hline $15-23$ & 0.0000 & 0.0000 & 0.0000 & 0.0000 & 0.0000 & 0.0000 & 0.0222 & 1.0000 & 0.0222 & 0.0222 \\
\hline $16-17$ & 0.0000 & 0.0000 & 0.8484 & 0.0000 & 0.2161 & 0.2161 & 0.6387 & 0.6387 & 0.6387 & 0.6387 \\
\hline
\end{tabular}


Table 5 The distribution of Junction points in the IEEE-30 bus testing system (Continued)

\begin{tabular}{lllllllllll}
\hline $18-19$ & 0.3696 & 0.4804 & 1.0000 & 1.0000 & 1.0000 & 1.0000 & 0.4348 & 0.4348 & 0.4348 & 0.4348 \\
$19-20$ & 0.0000 & 0.0000 & 0.9278 & 0.1898 & 0.1898 & 0.1898 & 0.0000 & 0.0000 & 0.0000 & 0.0000 \\
$21-22$ & 1.0000 & 0.0000 & 0.0000 & 0.0000 & 0.0000 & 0.0000 & 0.0000 & 0.3806 & 0.0000 & 0.0000 \\
$22-24$ & 1.0000 & 1.0000 & 0.0000 & 0.0000 & 0.0000 & 0.0000 & 0.0000 & 1.0000 & 0.0000 & 0.0000 \\
$23-24$ & 0.0000 & 0.0000 & 1.0000 & 0.0000 & 0.0000 & 0.0000 & 0.0000 & 0.4239 & 0.0000 & 0.0000 \\
$24-25$ & 1.0000 & 1.0000 & 1.0000 & 1.0000 & 0.0000 & 0.0000 & 0.0000 & 0.0062 & 0.0000 & 0.0000 \\
$25-26$ & 1.0000 & 1.0000 & 1.0000 & 1.0000 & 1.0000 & 0.0000 & 1.0000 & 1.0000 & 1.0000 & 1.0000 \\
$25-27$ & 1.0000 & 1.0000 & 1.0000 & 1.0000 & 1.0000 & 1.0000 & 0.0000 & 0.0000 & 0.0000 & 0.0000 \\
$27-28$ & 0.0521 & 0.1849 & 0.6875 & 0.9922 & 1.0000 & 1.0000 & 1.0000 & 0.0000 & 1.0000 & 1.0000 \\
$27-29$ & 1.0000 & 1.0000 & 1.0000 & 1.0000 & 1.0000 & 1.0000 & 1.0000 & 1.0000 & 0.0000 & 0.3929 \\
$27-30$ & 1.0000 & 1.0000 & 1.0000 & 1.0000 & 1.0000 & 1.0000 & 1.0000 & 1.0000 & 0.1080 & 0.0000 \\
$29-30$ & 0.1577 & 0.1577 & 0.1577 & 0.1577 & 0.1577 & 0.1577 & 0.1577 & 0.1577 & 1.0000 & 0.0000 \\
\hline
\end{tabular}

Table 6 Minimum and Maximum section connecting points for each line

\begin{tabular}{|c|c|c|}
\hline Lines & Minimum section connecting point & Maximum section connecting point \\
\hline $1-2$ & $\begin{array}{l}{[2,4,5,6,7,8,9,10,11,12,13,14,15,16,17,18,19,20,21} \\
22,23,24,25,26,27,28,29,30]\end{array}$ & {$[1,3]$} \\
\hline $1-3$ & [3] & {$[1,2,5]$} \\
\hline $2-4$ & {$[4,12,13,14,15,16,18,23]$} & {$[1,2]$} \\
\hline $2-5$ & {$[5,7]$} & {$[1,2,3]$} \\
\hline $2-6$ & {$[6,8,9,10,11,17,19,20,21,22,24,25,26,27,28,29,30]$} & {$[1,2]$} \\
\hline $3-4$ & $\begin{array}{l}{[4,6,7,8,9,10,11,12,13,14,15,16,17,18,19,20,21,22,23,} \\
24,25,26,27,28,29,30]\end{array}$ & [3] \\
\hline $4-6$ & {$[5,6,7,8,9,10,11,19,20,21,22,25,26,27,28,29,30]$} & {$[3,4,12,13,14,15,16,18,23]$} \\
\hline $4-12$ & {$[12,13,14,15,16,17,18,23,24]$} & {$[1,2,3,4,5,6,7,8,9,10,11,20,21,22,25,26,27,28,29,30]$} \\
\hline $5-7$ & $\begin{array}{l}{[4,6,7,8,9,10,11,12,13,14,15,16,17,18,19,20,21,22,23,} \\
24,25,26,27,28,29,30]\end{array}$ & {$[1,2,5]$} \\
\hline $6-7$ & {$[5,7]$} & $\begin{array}{l}{[3,4,6,8,9,10,11,12,13,14,15,16,17,18,19,20,21,22,23,24} \\
25,26,27,28,29,30]\end{array}$ \\
\hline $6-8$ & [8] & $\begin{array}{l}{[1,2,3,4,5,6,7,8,9,10,11,12,13,14,15,16,17,18,19,20,21} \\
22,23,24]\end{array}$ \\
\hline $6-9$ & {$[9,11]$} & {$[1,2,3,4,5,6,7,8,12,13,14,15,27,28,29,30]$} \\
\hline $6-10$ & {$[10,17,19,20,21,22,24]$} & {$[1,2,3,4,5,6,7,8,12,13,14,27,28,29,30]$} \\
\hline $6-28$ & {$[25,26,27,28,29,30]$} & {$[1,2,3,4,5,6,7,8,9,10,11,12,13,14,15,16,17,18,19,20,21,22,23,24]$} \\
\hline $8-28$ & {$[25,26,27,28,29,30]$} & [8] \\
\hline $9-10$ & {$[10,16,17,18,19,20,21,22,23,24,25,26]$,} & {$[9,11]$} \\
\hline $9-11$ & [11] & $\begin{array}{l}{[1,2,3,4,5,6,7,8,9,10,12,13,14,15,16,17,18,19,20,21,22,23,24,25,} \\
26,27,28,29,30]\end{array}$ \\
\hline $10-17$ & {$[16,17]$} & $\begin{array}{l}{[1,2,5,6,7,8,9,10,11,19,20,21,22,23,24,25,26,27,28,29} \\
30]\end{array}$ \\
\hline $10-20$ & {$[18,19,20]$} & $\begin{array}{l}{[1,2,3,4,5,6,7,8,9,10,11,12,13,14,15,16,21,22,23,24,25,26,27,28} \\
29,30]\end{array}$ \\
\hline $10-21$ & {$[21]$} & {$[1,2,3,4,5,6,7,8,9,10,11,12,13,16,17,19,20,28]$} \\
\hline $10-22$ & {$[22,23,24,25,26]$} & {$[1,2,3,4,5,6,7,8,9,10,11,12,13,16,17,19,21,28]$} \\
\hline $12-13$ & [13] & $\begin{array}{l}{[1,2,3,4,5,6,7,8,9,10,11,12,14,15,16,17,18,19,20,21,22,23,24,25,} \\
26,27,28,29,30]\end{array}$ \\
\hline $12-14$ & {$[14]$} & {$[1,2,3,4,5,6,7,8,9,10,11,12,13,16,17,20,27,28,29,30]$} \\
\hline
\end{tabular}


Table 6 Minimum and Maximum section connecting points for each line (Continued)

\begin{tabular}{lll}
\hline $12-15$ & {$[15,18,19,23,24]$} & {$[1,2,3,4,5,6,7,8,9,11,12,13,16,17,27,28,29,30]$} \\
$12-16$ & {$[16,17]$} & {$[1,2,3,4,5,6,7,8,12,13,14,15,18,23,25,26,27,28,29,30]$} \\
$14-15$ & {$[15,18,19,21,22,23,24,25,26]$} & {$[14]$} \\
$15-18$ & {$[10,18,19,20]$} & {$[1,2,3,4,5,6,7,8,12,13,14,15,16,17,21,22,23,24,25,26,27,28,29,30]$} \\
$15-23$ & {$[21,22,23,24,25,26]$} & {$[1,2,3,4,5,6,7,8,12,13,14,15,16,17,18,19,28]$} \\
$16-17$ & {$[9,10,11,17,19,20,21,22,24]$} & {$[3,4,12,13,14,15,16,18]$} \\
$18-19$ & {$[9,10,11,19,20]$} & {$[12,13,14,15,18,23,24,25,26]$} \\
$19-20$ & {$[1,2,3,4,5,6,7,8,9,10,11,16,17,21,22,27,28,29,30]$} & {$[15,18,19,20]$} \\
$21-22$ & {$[14,15,18,22,23,24,25,26,27,29,30]$} & {$[21]$} \\
$22-24$ & {$[14,15,18,23,24,25,26,27,29,30]$} & {$[1,2,5,6,7,8,9,10,11,16,17,20,21,22,28]$} \\
$23-24$ & {$[9,10,11,17,20,21,22,24,25,26,27,29,30]$} & {$[3,4,12,13,14,15,18,19,23]$} \\
$24-25$ & {$[25,26,27,29,30]$} & {$[9,10,11,14,15,17,18,19,20,21,22,23,24]$} \\
$25-26$ & {$[26]$} & {$[1,2,3,4,5,6,7,8,9,10,11,12,13,14,15,16,17,18,19,20,21,22,23,24$,} \\
& & $25,27,28,29,30]$ \\
$25-27$ & {$[1,2,3,4,5,6,7,8,12,13,16,27,28,29,30]$} & {$[21,22,23,24,25,26]$} \\
$27-28$ & {$[1,2,3,4,5,6,7,8,9,10,11,12,13,14,15,16,17,18,19,20,28]$} & {$[25,26,27,29,30]$} \\
$27-29$ & {$[\mathbf{2 9}]$} & {$[1,2,3,4,5,6,7,8,9,10,11,12,13,14,15,16,17,18,19,20,21,22,23,24$,} \\
$27-30$ & & $25,26,27,28]$ \\
$29-30$ & {$[30]$} & {$[1,2,3,4,5,6,7,8,9,10,11,12,13,14,15,16,17,18,19,20,21,22,23,24$,} \\
& & $25,26,27,28]$
\end{tabular}

\section{Acknowledgement}

Project supported by the Key Project of Smart Grid Technology and Equipment of National Key Research and Development Plan of China (2016YFB0900600), Project supported by the National Natural Science Foundation Fund for Distinguished Young Scholars(51425701), the National Natural Science Foundation of China(51207013), the Hunan Province Natural Science Fund for Distinguished Young Scholars(2015JJ1001), the Education Department of Hunan Province Project(15C0032).

\section{Competing interests}

No conflict of interest exits in the submission of this manuscript, and manuscript is approved by all authors for publication. I would like to declare on behalf of my co-authors that the work described was original research that has not been published previously, and not under consideration for publication elsewhere, in whole or in part. All the authors listed have approved the manuscript that is enclosed.

\section{Authors' contributions}

FD writing paper; propose the new method; simulation analysis. XJZ is the supervisor the first author; revise the whole paper. LLP revises the simulation analysis. All authors read and approved the final manuscript.

\section{Author details}

'Changsha University of Science and Technology, Changsha, Hunan, China. ${ }^{2}$ State Grid Hubei Yichang Electric Power Supply Company, Yichang, Hubei, China.

Received: 31 December 2016 Accepted: 13 March 2017

Published online: 10 May 2017

\section{References}

1. Sharafi A., Sanaye-Pasand A., \& Jafarian P. (2011). Ultra-high-speed protection of parallel transmission lines using current travelling waves. IET Gen Transm Distrib, 6(5), 656-666.

2. Korkali, M., Lev-Ari, H., \& Abur, A. (2012). Traveling-wave-based fault location technique for transmission grids via wide-area synchronized voltage measurements. IEEE Transactions on Power Systems, 27(2), 1003-1011.
3. Nanayakkara, O. M. K. K., Rajapakse, A. D., \& Wachal, R. (2012). Location of dc line faults in conventional HVDC systems with segments of cables and overhead lines using terminal measurements. IEEE Transactions on Power Delivery, 27(1), 279-288.

4. Korkali, M., \& Abur, A. (2010). Fault location in meshed power networks using synchronized measurements. In Proc. North American Power Symp (pp. 1-6).

5. Kim, G., Kim, H., \& Choi, J. (2001). Wavelet transform based power transmission line fault location using GPS for accurate time synchronization. In Proc. IEEE Power Eng. Soc. Transm. and Distribution Conf (Vol. 1, pp. 495-499).

6. Spoor, D., \& Zhu, J. G. (2006). Improved single-ended traveling-wave fault location algorithm based on experience with conventional substation transducers. IEEE Transactions on Power Delivery, 21(3), 1714-1720.

7. Lee, H., \& Mousa, A. M. (1996). GPS traveling wave fault locator systems: investigation into the anomalous measurements related to lightning strikes. IEEE Transactions on Power Delivery, 11(3), 1214-1223.

8. Deng, F., Zeng, X., \& Chen, N. (2009). A network-adapted traveling-wave fault location method. Automation of Electric Power Systems, 33(19), 66-70. in Chinese.

9. Zhou, H., Zeng, X., Deng, F., \& Liu, H. (2013). A New Network-based Algorithm for Transmission Line Fault Location with Traveling Wave. Automation of Electric Power Systems, 37(17), 93-99.

10. Zhu, Y., Fan, X., \& Yin, J. (2012). A New Fault Location Scheme for Transmission Lines Based on Traveling Waves of Three Measurements. Transactions of China Electro-technical Society, 27(3), 261-268.

11. Korkali, M., \& Abur, A. (2013). Optimal Deployment of Wide-Area Synchronized Measurements for Fault-Location Observability. IEEE Transactions on Power Systems, 28(1), 482-489.

12. Evrenosoglu, C. Y., \& Abur, A. (2005). Travelling wave based fault location for teed circuits. IEEE Transactions on Power Delivery, 20(2), 1115-1121.

13. Azizi, S., Sanaye-Pasand, M., Abedini, M., \& Hasani, A. (2014). A TravelingWave-Based Methodology for Wide-Area Fault Location in Multi-terminal DC Systems. IEEE Transactions on Power Delivery, 29(6), 2552-2560.

14. Zewen, L., Xiangjun, Z., Jiangang, Y., Feng, D., \& Huanhuan, H. (2014). Wide area traveling wave based power grid fault network location method. Electrical Power and Energy Systems, 14(5), 173-176. 
15. Zhao, J., Wen, F., Xue, Y., \& Lin, Z. (2010). Cloud Computing Implementing an Essential Computing Platform for Future Power Systems. Automation of Electric Power Systems, 34(15), 2-8.

16. Zhang D., Ding H., Hao X., Zhao Y., \& Sun Y. (2011). Cloud computing structure of power system faced smart grid. Proceedings of electric power communication management and smart grid communication technology conference.

17. Bo, Z. Q. (2014). The Application of cloud computing for smart substations and new energy integrations. China: 2014 Global Smart Grid Conference.

18. Liao, Y. (2009). Fault location observability analysis and optimalmeter placement based on voltage measurements. Electric Power Systems Research, 79(7), 1062-1068.

19. Lien, K. P., Liu, C. W., Yu, C. S., \& Jiang, J. A. (2006). Transmission network fault location observability with minimal PMU placement. IEEE Transactions on Power Delivery, 21(3), 1128-1136.

\section{Submit your manuscript to a SpringerOpen ${ }^{\circ}$ journal and benefit from:}

- Convenient online submission

- Rigorous peer review

- Immediate publication on acceptance

- Open access: articles freely available online

- High visibility within the field

- Retaining the copyright to your article

Submit your next manuscript at $\boldsymbol{s p r i n g e r o p e n . c o m ~}$ 